\title{
Protée
}

\section{Françoise Sullivan}

\section{Thérèse Saint-Gelais}

Volume 26, numéro 3, 1998

Logique de l’icône

URI : https://id.erudit.org/iderudit/030527ar

DOI : https://doi.org/10.7202/030527ar

Aller au sommaire du numéro

Éditeur(s)

Département des arts et lettres - Université du Québec à Chicoutimi

\section{ISSN}

0300-3523 (imprimé)

1708-2307 (numérique)

Découvrir la revue

\section{Citer cet article}

Saint-Gelais, T. (1998). Françoise Sullivan. Protée, 26(3), 65-67.

https://doi.org/10.7202/030527ar d'utilisation que vous pouvez consulter en ligne.

https://apropos.erudit.org/fr/usagers/politique-dutilisation/ 


\section{FRANÇOISE SULLIVAN}

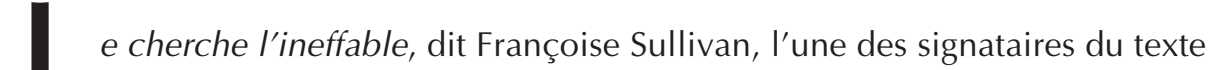 pamphlétaire le plus célèbre en art québécois, Refus global. Un ineffable, nous semble-t-il, qui ne peut prendre forme que par la peinture et, de façon plus}

explicite encore, par l'abstraction. Sullivan peint depuis longtemps mais, depuis seulement quelques années, seul un travail fait à partir d'une couleur dominante, voire unique, arrive à la satisfaire. La simplification ici est moins un but recherché qu'une manière de peindre toujours à revoir, même à éprouver.

Chez Sullivan, la proposition picturale ne s'adresse pas uniquement au regard, mais au corps, à la pensée et à la sensibilité, pour ne pas dire à l'âme, comme chez les Anciens. Ni la première, ni la seule à s'investir corps et «âme» dans cette entreprise, il demeure qu'elle le fait avec son passé d'automatiste - sa relation indissociable au geste et à la danse - combiné à sa paradoxale appartenance au modernisme et au postmodernisme. Commentant ses liens avec I'automatisme, elle fait intervenir le subconscient comme lieu de passage déterminant dans la facture de sa toile. Également, elle signifie, et ça se voit devant le tableau, son rapport au «faire», mené par une traversée littéralement corporelle de l'espace, aussi plat soit-il. Tel un éclaireur, le pinceau (ou la craie) tâte la surface et glisse dans sa minceur l'épaisseur du corps. L'espace de la toile prend soudain de l'ampleur. De même, c'est au tracé gestuel que se lit la corporéité de l'artiste dans l'œuvre.

Danseuse et chorégraphe, Sullivan proposait une gestuelle théâtrale; sculpteure, elle a joué de l'espace qui devenait alors la scène d'une transformation; peintre de grands mythes grecs et d'œuvres tondos (auxquels elle ajoutait des matériaux «pauvres»), elle ne semble pouvoir maintenant penser sa peinture autrement que comme un «événement poétique » 1 , activé par le désir de faire avec un vocabulaire chromatique et gestuel simplifié.

Devant son support, Sullivan se fait économe. Non pas parce qu'elle viserait la représentation du « rien » (pas plus que sa libération d'ailleurs, pour évoquer ici la démarche de Malévitch), mais pour tenter d'incorporer en un même lieu l'éloquence du dépouillement et 
I'intensité d'une présence. Comment nommer cette figure qui relèverait du comble et de l'épuration à la fois? Est-ce là une nouvelle représentation du sublime? Ou une nouvelle tentative de représenter l'irreprésentable? «L'ineffable», dit-elle.

Délibérément quasi monochromes, carrés ou rectangulaires, présentés par paires ou par unités, les tableaux de Sullivan n'ont rien de l'icône malévitchéen où une dimension spirituelle, voire mystique, prévaut. La corporéité de l'artiste y est trop prégnante et engage de trop près également le corps de l'autre. Tout entière sensible, l'œuvre ne se défend pas pour autant à partir de sa seule matérialité. Sous la couleur, entre les tracés, au cœur toujours déplacé d'un champ coloré, I' «événement» advient, portant en lui sa charge de résonance.

De cette étape dans la carrière de Sullivan, l'on dira qu'elle revient à la peinture, en laquelle elle croit depuis toujours comme matériau et médium inépuisable d'expressions de toutes sortes. Or, à l'image du mouvement même qu'est le retour, elle nous semble tenter un réapprentissage du métier, une nouvelle maîtrise de la couleur, qui ne peut se faire, chez elle, sans reconsidérer le langage pictural dans ses manifestations à la fois les plus sensibles et les plus muettes.

Thérèse Saint-Gelais

1. J'emprunte cette expression à Yves Klein, alors qu'il commente son rapport à la couleur. Voir D. Riout, La Peinture monochrome. Histoire et archéologie d'un genre, Nîmes, Éd. Jacqueline Chambon, 1996.

Thérèse Saint-Gelais est adjointe à la rédaction à la revue Parachute et enseigne l'histoire de l'art à l'Université du Québec à Montréal. Elle a publié de nombreux textes dont plusieurs portent sur l'art et les femmes, problématique privilégiée dans son mémoire de maîtrise et sa thèse de doctorat. 


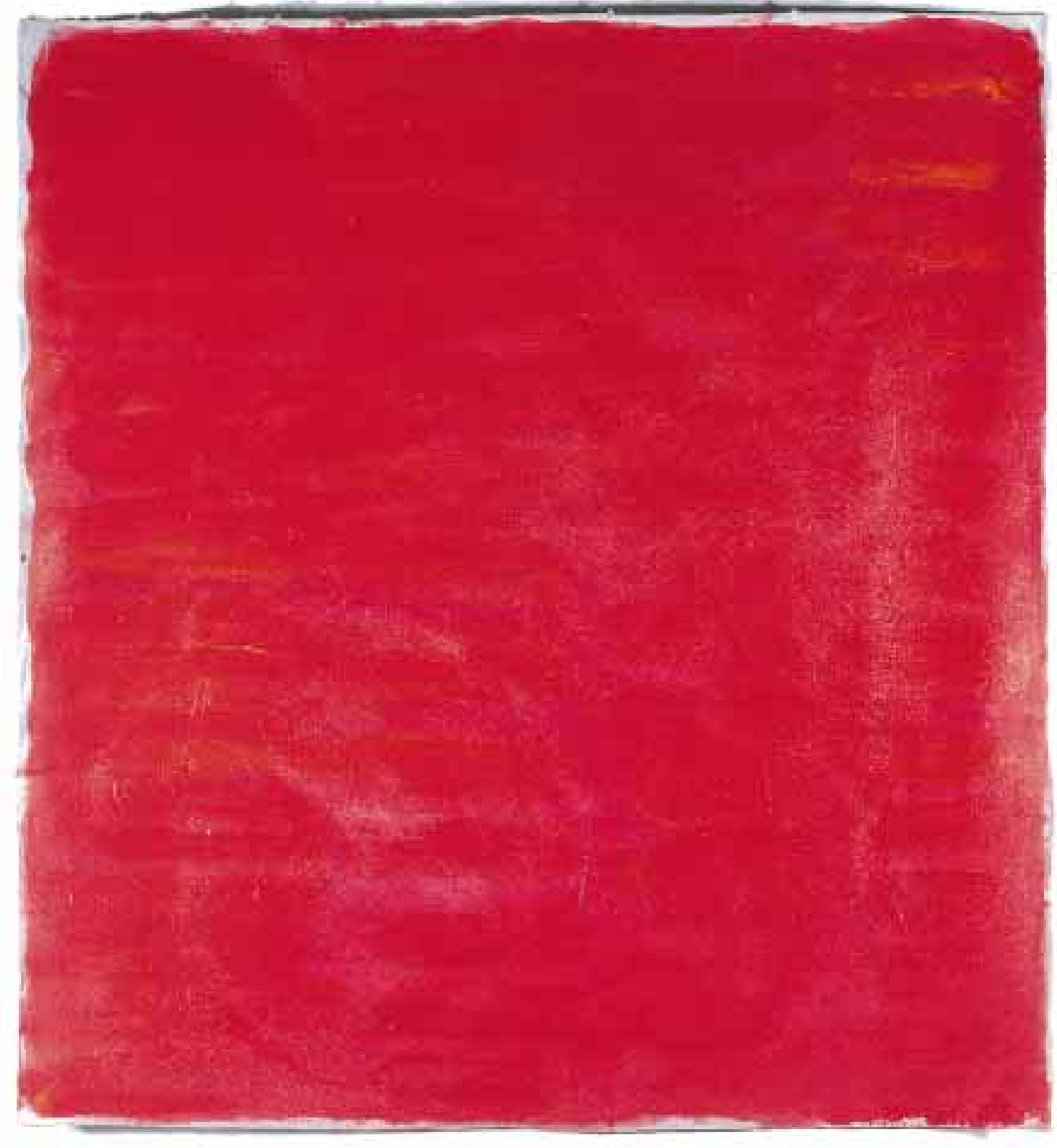

Françoise Sullivan, Rouge, 1998, nu-pastel sur papier, 1,19 x 1,11 m. Photographie: Françoise Sullivan. 